\title{
Global statistical analysis of TOPEX and POSEIDON data
}

\author{
P. Y. Le Traon, J. Stum, J. Dorandeu, and P. Gaspar \\ Collecte Localisation Satellites, Space Oceanography Group, Toulouse, France
}

\section{P. Vincent ${ }^{1}$}

Groupe de Recherches de Géodésie Spatiale, Centre National d'Etudes Spatiales, Toulouse, France

\begin{abstract}
A global statistical analysis of the first 10 months of TOPEX/POSEIDON merged geophysical data records is presented. The global crossover analysis using the Cartwright and Ray (1990) (CR) tide model and Gaspar et al. (this issue) electromagnetic bias parameterization yields a sea level RMS crossover difference of $10.05 \mathrm{~cm}, 10.15 \mathrm{~cm}$, and $10.15 \mathrm{~cm}$ for TOPEX-TOPEX, POSEIDON-POSEIDON, and TOPEX-POSEIDON crossovers, respectively. All geophysical corrections give reductions in the crossover differences, the most significant being with respect to ocean tides, solid earth tide, and inverse barometer effect. Based on TOPEX-POSEIDON crossovers and repeat-track differences, we estimate the relative bias between TOPEX and POSEIDON at about $-15.5 \pm 1 \mathrm{~cm}$. This value is dependent, however, to the electromagnetic bias corrections used. An orbit error reduction method based on global minimization of crossover differences over one cycle yields an orbit error of about 3 $\mathrm{cm}$ RMS. This is probably an upper estimate of the orbit error since the estimation absorbs other altimetric signals. The RMS crossover difference is reduced to $8.8 \mathrm{~cm}$ after adjustment. A repeat-track analysis is then performed using the CR tide model. In regions of high mesoscale variability, the RMS sea level variability agrees well with the Geosat results. Tidal errors are also clearly evidenced. A recent tide model (Ma et al., this issue) determined from TOPEX/POSEIDON data considerably improves the RMS sea level variability. The reduction of sea level variance is $(4 \mathrm{~cm})^{2}$ on average but can reach $(8 \mathrm{~cm})^{2}$ in the southeast Pacific, southeast Atlantic, and Indian Oceans. The RMS sea level variability thus decreases from $6 \mathrm{~cm}$ to only $4 \mathrm{~cm}$ in quiet ocean regions. The large-scale sea level variations over these first 10 months most likely show for the first time the global annual cycle of sea level. Finally, we analyze the TOPEX and POSEIDON sea level anomaly wavenumber spectral characteristics. TOPEX and POSEIDON have identical spectral characteristics at low wavenumbers. For wavelengths shorter than $100 \mathrm{~km}$, however, POSEIDON spectra are more energetic. This is probably related to the TOPEX tracker characteristics and to the way the acceleration correction is made in the geophysical data records. POSEIDON repeattrack noise level is estimated at about $3 \mathrm{~cm}$ for a $1-\mathrm{s}$ average. The TOPEX repeat-track noise level is about $1.8 \mathrm{~cm}$ RMS but this probably corresponds to averages over several seconds.
\end{abstract}

\section{Introduction}

The main objective of the joint United States/French TOPEX/POSEIDON mission is to determine the general circulation of the ocean and its variability [e.g., Stewart et al., 1986]. This is a very challenging objective. Unlike the mesoscale ocean signal, the basin-scale ocean circulation variability is weak. It also decorrelates less easily from altimetric measurement errors and in particular from orbit error. Observing the absolute or mean circulation also calls for precise orbits and a precise and independent geoid. TOPEX/POSEIDON is thus particularly optimized to provide the most accurate measurements of the absolute circu-

\footnotetext{
${ }^{1}$ Now at Centre National d'Etudes Spatiales, Division TerreUnivers, Toulouse, France.

Copyright 1994 by the American Geophysical Union.

Paper number $94 \mathrm{JC} \mathrm{C} 1110$.

0148-(0227/94/94JC-01110\$05.00
}

lation and of its variability. Three systems (Doppler orbitography and radiopositioning integrated by satellite (DORIS), laser, and Global Positioning System) are providing very precise, global tracking of the satellite orbit. The height measurements are done by NASA's TOPEX dual-frequency altimeter and the Centre National d'Etudes Spatiales (CNES) experimental POSEIDON altimeter. The NASA three-channel TOPEX microwave radiometer (TMR) is used in addition to correct for propagation effects in the troposphere.

Since its successful launch on August 10, 1992, TOPEX/ POSEIDON has been measuring the global sea surface height along the same tracks on Earth every 10 days. The verification phase started soon after launch and lasted 6 months. Merged interim geophysical data records (IGDR-M) cycles were rapidly distributed to the scientific community for validation. After extensive analysis of these preliminary data, algorithms, geophysical corrections, and in particular orbit accuracies were improved for the operational phase. 
Distribution of the final products (merged geophysical data records) started in June 1993. TOPEX/POSEIDON data are being distributed to the scientific community by Physical Oceanography Distributed Active Archive Center (PODAAC) for the Jet Propulsion Laboratory (JPL) and AVISO for CNES. AVISO is the French TOPEX/POSEIDON data processing and distribution center set up by CNES at Collecte Localisation Satellites (CLS). AVISO also performs systematic, global analyses of TOPEX/POSEIDON merged products as part of AVISO Quick-Look activities. These activities consist in validating TOPEX/POSEIDON data and generating quick-look and higher level products. We present here results of these global analyses applied to the first 10 months of TOPEX/ POSEIDON merged geophysical data records. The objective is to provide a first global assessment of TOPEX/POSEIDON (almost) final data set. Several important questions need to be answered. Are the TOPEX and POSEIDON altimeters compatible and can they be merged in the analyses? What are the noise measurement levels of the two altimeters? How large are the residual orbit and tidal errors and how do they affect the large scale ocean signal?

The global statistical analysis presented in this paper is intended to discuss these key issues and to provide an overview of TOPEX and POSEIDON data quality. The paper is organized as follows. Section 2 describes the processing of TOPEX/POSEIDON data. Section 3 provides results of global crossover analysis. Section 4 deals with the repeat-track analysis, the large-scale ocean signal analysis, and the characterization of TOPEX and POSEIDON wavenumber spectra of sea level anomaly. Main results are summarized in the conclusion.

\section{Data Editing and Validation}

We used the first 32 cycles of merged geophysical data records (GDR-M) [AVISO, 1992] distributed by AVISO, that is, cycle 1 to cycle 32 . Because of an attitude problem, cycle 1 was however rejected a priori. The attitude control of TOPEX/POSEIDON was actually completely solved only starting from the end of cycle 9. POSEIDON operated throughout cycle 20 and cycle 31 and about $10 \%$ of the time during cycles $3,4,5,6,8$ and from cycle 11 to cycle 16 . TOPEX operated all the time during the remaining cycles. Half the data for cycle 31 were lost and cycles 31 and 32 will be used here only for estimating the relative bias between TOPEX and POSEIDON and analyzing POSEIDON spectral characteristics. The data were first edited to remove bad height measurements (e.g., due to ice and rain contamination) and/or bad or missing corrections. Because of different tracker characteristics we applied different range measurement quality criteria for TOPEX and POSEIDON. Figures $1 \mathrm{a}$ and $1 \mathrm{~b}$ show the scatter diagram of sigma- $h$ (RMS of range measurements over $1 \mathrm{~s}$ ) versus significant wave height (H $1 / 3$ ) for TOPEX (cycle 21) and POSEIDON (cycle 20), respectively. Sigma $-h$ for TOPEX is typically half as large as sigma- $h$ for POSEIDON. This is both because TOPEX sigma- $h$ is calculated from $1 / 10$-s averaged data points (instead of $1 / 20$-s data for POSEIDON) and because TOPEX $1 / 10$-s data are morc correlated and less noisy. Note also the H $1 / 3$ dependence of POSEIDON sigma- $h$ (i.e., measurement noise), as expected from simulations (O. Z. Zanife, personal communication, 1994). Based on these diagrams, we chose to reject POSEIDON data with a sigma- $h$ larger than $20 \mathrm{~cm}$ and TOPEX data with a sigma- $h$ larger than 10 $\mathrm{cm}$. In addition, we rejected data for which less than 10 (POSEIDON) or 5 (TOPEX) elementary data were available or for which the attitude (as given from waveform analysis) was larger than 0.4 degrees. We also used the ice and land (for radiometer) flags present in the geophysical data record (GDR) to reject data over ice and over land and removed data without tide corrections, with the TMR wet tropom spheric correction larger than $50 \mathrm{~cm}$ or with $H$ 1/3 larger than $11 \mathrm{~m}$. Finally, to eliminate spikes still present in the data we used an iterative process based on cubic spline functions [Le Traon et al., 1990] although it removed less than $0.01 \%$ of the data. The averaged value of nonland rejected points for the processed data was about $10 \%$. Figure 2 shows, for example, the percentage of nonvalid data for cycle 20 . Note that apart from ice regions, nonvalid data are concentrated in tropical convergence zones where rain is likely to occur and in regions with large significant wave height.

The sea surface height (SSH) measurements were obtained using the CNES orbit. Note that the NASA orbit could be used as well since the two orbits agree to within a few centimeters [e.g., Noucl et al., this issue]. They were then corrected for the following effects. Electromagnetic bias for TOPEX and POSEIDON was estimated using the $F_{u}$ and Glazman [1991] parameterization. The electromagnetic (em) bias is expressed according to significant wave height SWH, wind speed $U$, and gravity $g$ as $\alpha$ SWH $(g \mathrm{SWH} /$ $\left.U^{2}\right)^{-0.5}$. Variable $\alpha$ was set to -0.01 for TOPEX and to -0.016 for POSEIDON. These values were derived from a preliminary global crossover analysis of TOPEX/ POSEIDON data [Gaspar et al., this issue]. The Cartwright and Ray [1990] (hereinafter referred to as CR) and Ray and Sanchez. [1989] models were used for ocean and loading tides. In the Mediterranean Sea we used the Groupe de Recherches de Géoidésie Spatiale (GRGS) model (P. Canceil et al., unpublished manuscript, 1994). Solid Earth tides were obtained from the Cartwright and Taylor [1971] model. Ionospheric effects were derived from TOPEX dualfrequency measurements filtered with a Lanczos low-pass filter with a cutoff wavelength of $150 \mathrm{~km}$ for TOPEX and from DORIS measurements for POSEIDON. Dry tropospheric and inverse barometer effects were calculated using data from the European Center for Medium-Range Weather Forecasting (ECMWF) and wet tropospheric corrections from the TMR radiometer.

\section{Crossover Analysis}

Analyzing the crossover differences is a good way of assessing the effectiveness of altimeter corrections and evaluating the orbit error amplitude. Each crossover provides a measurement of the variation $\Delta S_{m}$ in measured sea surface topography between an ascending and descending arc. If the two arcs are close together in time, most of the variation can be attributed to orbit error and errors in altimeter correction. This will be the case here since crossovers are calculated over each cycle so that the maximum time difference is below 10 days. The principle of the method is to analyze the variance of $\Delta S_{m}$ and how it varies depending on the corrections applied to the data. A correction will be considered effective provided it decreases the variance of $\Delta S_{m}$. This assumes that there is no anticorrelation between different 

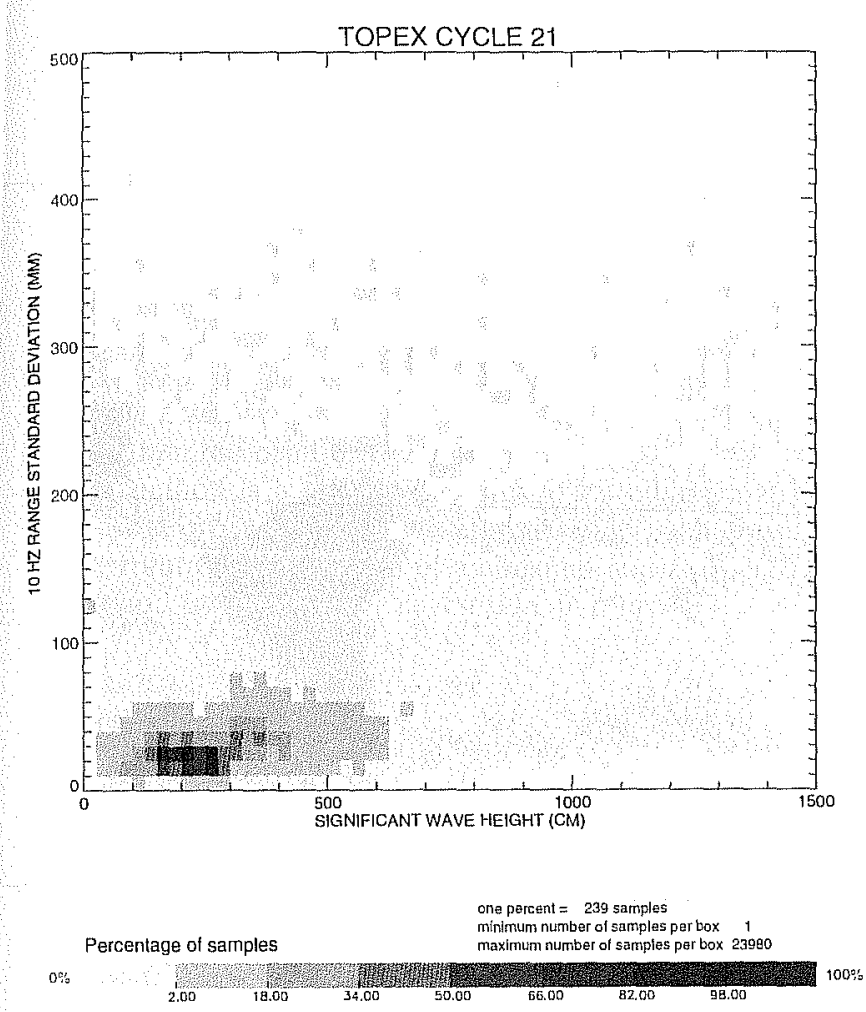

Figure 1a. Scatter diagram of sigma- $h$ (RMS of range measurements over $1 \mathrm{~s}$ ) versus significant wave height $\left(\begin{array}{lll}H & 1 / 3\end{array}\right)$ for TOPEX (cycle 21). Grey levels indicate the relative number of data in $25 \mathrm{~cm}(H 1 / 3)-1 \mathrm{~cm}($ sigma- $h)$ boxes.

corrections or real changes in the sea surface topography, which makes sense for a global analysis of a cycle [e.g., Ray et al., 1991]. Note that this method allows us to assess the effectiveness of the correction for short timescales only. This is because long timescale variations (e.g., seasonal) have almost no signature at crossovers with small time differences.

\subsection{Analysis of Crossover Differences}

Crossover points were calculated for each of the 29 processed cycles (cycle 2 to cycle 30 ) yielding three kinds of crossovers: TOPEX-TOPEX (T-T), TOPEX-POSEIDON (T-P), and POSEIDON-POSEIDON (P-P) crossovers. When the orbit error dominates the crossover differences, the RMS crossover difference can be translated roughly as $\sqrt{2}$ the RMS of the nongeographically correlated orbit error. This is no longer the case given that the TOPEX/POSEIDON orbit error is about $5 \mathrm{~cm}$ RMS [Nouel et al, this issue] and is no longer the dominant signal in crossover differences. Table 1 shows for the T-T crossovers the variance reduction in $\Delta S_{m}$ due to different geophysical corrections applied for the 29 processed cycles. The calculation is as by Ray et al. [1991]. The variance reduction for a correction $c_{i}$ is obtained from the difference between the variance with all corrections applied and the variance with all corrections except $c_{i}$ applied. The biggest reductions are obtained on ocean tide, solid Earth tide, and inverse barometer effect. The CR model reduces variance more than the Schwiderski [1980] model does. This is why we decided to use the Cartwright and Ray model for our final analyses. The TMR wet tropospheric correction performs slightly better than the correction de-
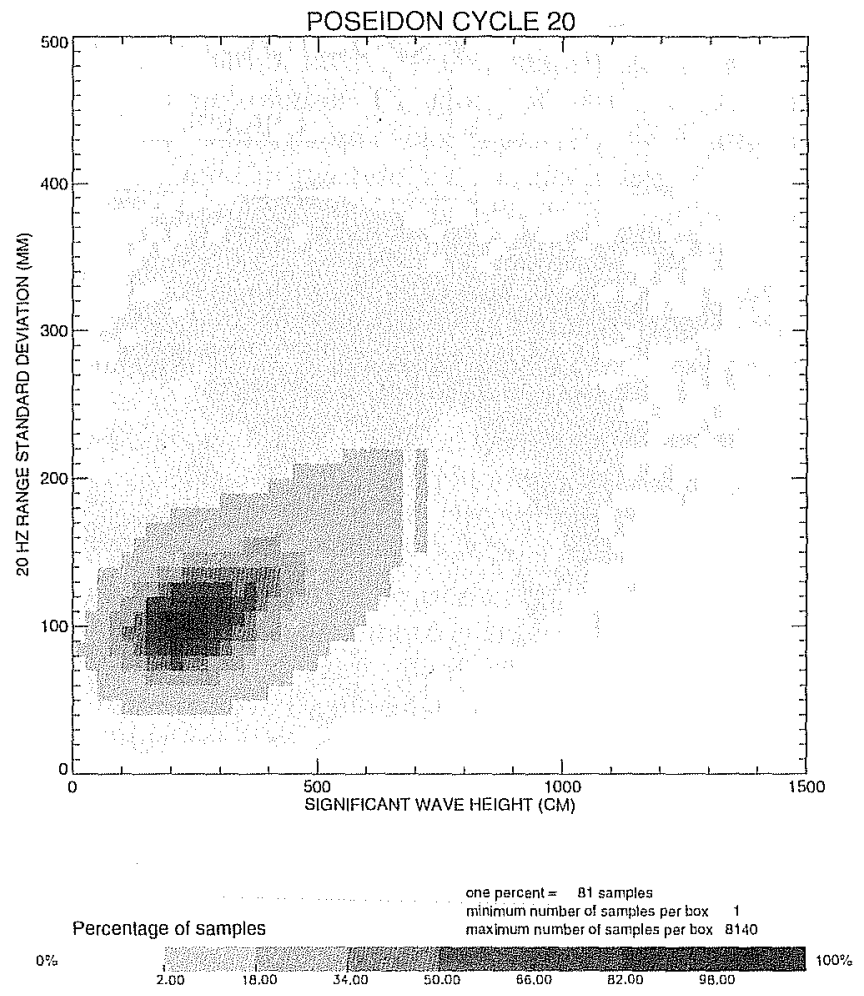

Figure 1b. Scatter diagram of sigma- $h$ (RMS of range measurements over $1 \mathrm{~s}$ ) versus significant wave height ( $H$ $1 / 3$ ) for POSEIDON (cycle 20).

rived from the meteorological model. A comprehensive comparison of TMR and ECMWF wet tropospheric corrections is given by Stum [this issue]. The dual-frequency ionospheric correction also performs slightly better than the DORIS and Bent ionospheric corrections. The recently proposed BM4 electromagnetic bias parameterization [Gaspar et al., this issue] which is based on a four-parameter model (em bias $=\mathrm{SWH}\left[a+b U+c U^{2}+d \mathrm{SWH}\right]$ ) also gives better variance reduction than the other models. The RMS of the T-T, T-P, and P-P crossover differences with all corrections applied for all processed cycles is between 10.5 and $12 \mathrm{~cm}$. There are only very slight differences between the CNES and NASA orbits. The mean of T-T RMS crossover difference for all processed cycles is $11.07 \mathrm{~cm}$ for CNES orbits and $11.14 \mathrm{~cm}$ for NASA orbits. If crossovers with differences larger than $30 \mathrm{~cm}$ are rejected, the means of the RMS differences (relative to the mean) over the 29 cycles are only $10.1,10.6$, and $10.6 \mathrm{~cm}$ for T-T, T-P, and P-P crossovers, respectively. The T-T, T-P, and P-P crossover differences are further reduced to just $10.05,10.15$, and 10.15 $\mathrm{cm}$ if the BM4 em bias parameterization is used. The difference in variance between TOPEX and POSEIDON crossover differences is thus only $2 \mathrm{~cm}^{2}$ which is not significant. The geographical distribution of the RMS of the crossover differences for all processed cycles (not shown) gives RMS values of about $7 \mathrm{~cm}$ RMS in quiet oceanic regions. This means that the orbit error is probably less than 5 cm RMS.

The mean TP crossover differences provides an estimate of the relative bias between the two altimeters. We found a value of $21.3 \mathrm{~cm}$, TOPEX measuring shorter. This result is based on 17,200 crossovers. A better means of estimating the 


\section{POSEIDON - Cycle 20 (Mar 31st to Apr 9th, 1993)}

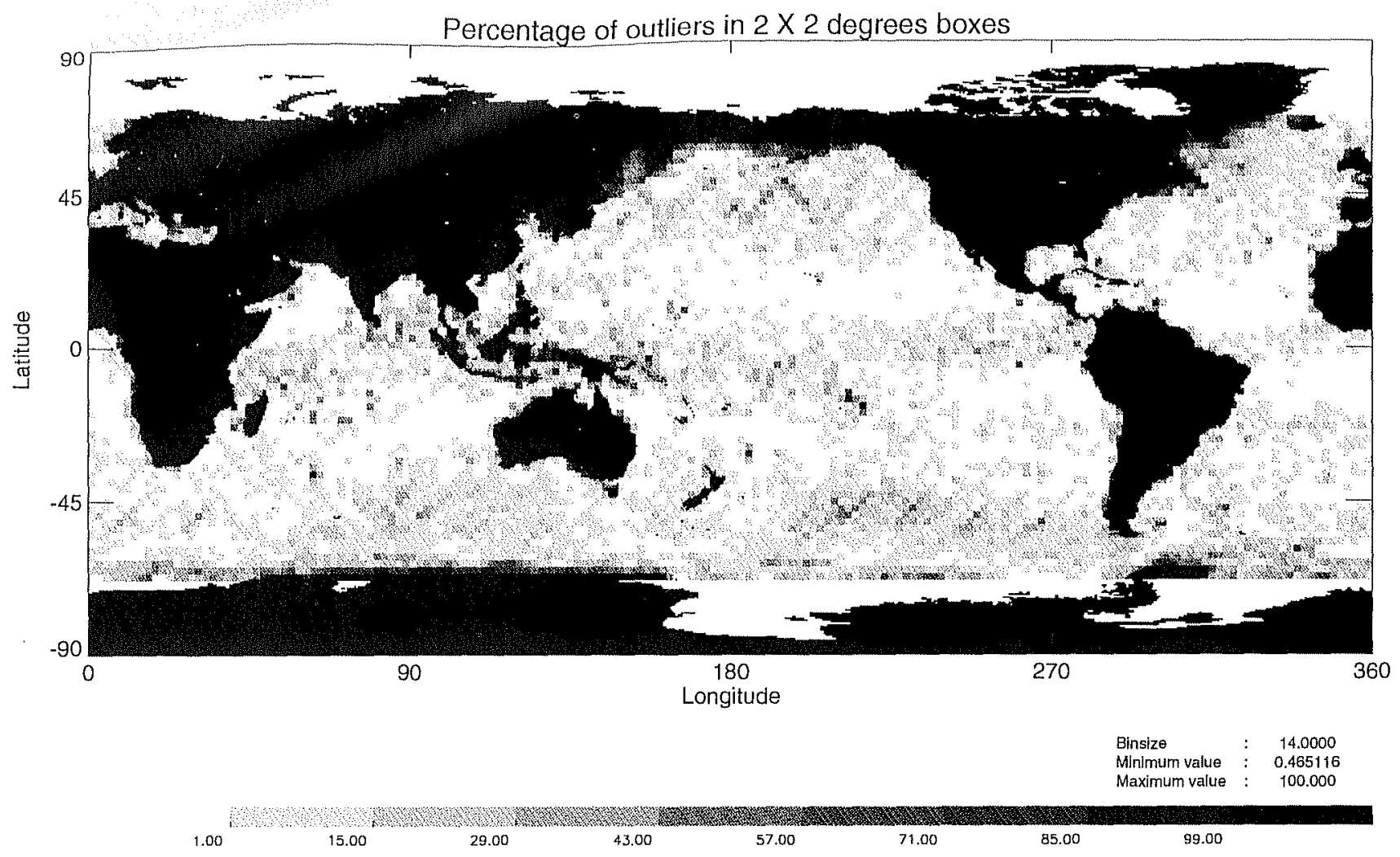

Figure 2. 'Percentage of nonvalid data for cycle 20.

relative bias is to use the difference between cycle 20 (where POSEIDON operated all the time) and cycles 19 and 21, respectively, from a repeat-track analysis using cycle 20 as the reference cycle. The mean over cycle 19 - cycle 20 is $20.7 \mathrm{~cm}$. The mean over cycle 21 - cycle 20 is $21.2 \mathrm{~cm}$. These estimations are based on more than 400,000 data points. A similar calculation was performed using cycle 31 and cycles 30 and 32 . The mean over cycle $30-$ cycle 31 is $19 \mathrm{~cm}$. The mean over cycle $32-$ cycle 31 is $20.1 \mathrm{~cm}$. These estimations are based on about 200,000 points (half of the cycle 31 data are missing). All our estimates are thus consistent to within $1.5 \mathrm{~cm}$. We thus estimate the relative bias at about $20.5 \pm 1 \mathrm{~cm}$. These estimations also include the bias between the TOPEX dual-frequency and DORIS ionospheric corrections which we estimated at about $1 \mathrm{~cm}$. Note that they also depend on the choice of em bias correction. The same calculations with the BM4 parameterization thus give a relative bias of about $15.5 \mathrm{~cm}$ only. This estimation is quite consistent with the difference between TOPEX and POSEIDON absolute biases estimated from on-site verification [Ménard et al., this issue; Christensen et al., this issue]. As can be seen from the RMS values of T-P crossover differences, TOPEX and POSEIDON are very consistent. T-T, T-P, and P-P crossover differences have comparable crossover differences. This means that POSEIDON and TOPEX data can be merged into a unique data set provided the bias corrections are done.

\subsection{Orbit Error Reduction}

From the previous analysis and precise orbit determination teams' results [e.g., Nouel et al, this issue], we expect the orbit error to be about $5 \mathrm{~cm}$ RMS at most. This very small figure challenges the usual orbit error reduction procedures or even the use of an orbit correction at all. The signal (i.e., orbit error) to noise (other corrections and ocean signal) ratio is indeed smaller than 1 . Commonly used orbit error reduction methods based on the repeat-track analysis and a polynomial adjustment, or even a sinusoidal approximation, are not suitable for TOPEX/POSEIDON. They remove the along-track long-wavelength ocean signals together with the orbit error. Global crossover minimization methods are more suitable [e.g., Tai and Fu, 1986; Tai, 1988]. They only remove the part of the ocean signal with a

Table 1. Signal Variance Explained in T-T Crossover Differences

\begin{tabular}{lc} 
& Variance, $\mathrm{cm}^{2}$ \\
\hline Ocean tide + loading tide CR & 1748 \\
Ocean tide + loading tide SCH & 1722 \\
Solid Earth tide & 165 \\
Inverse barometer + dry troposphere & 154 \\
Wet troposphere TMR & 14.3 \\
Wet troposphere ECMWF & 7.4 \\
TOPEX ionospheric correction & 14.1 \\
DORIS ionospheric correction & 12.8 \\
Bent ionospheric correction & 12.1 \\
em bias NASA & 9.3 \\
em bias CNES & 6.3 \\
em bias - BM4 & 10.4 \\
\hline
\end{tabular}

Cycles 2 to $30,150,280$ crossovers. Abbreviation SCH, Schwiderski. 
signature on crossover differences. If the adjustment is limited to crossovers with short time differences, most of the large-scale ocean signal can be preserved. We therefore decided to remove the one-cycle and two-cycles per revolution frequencies of the orbital error by minimizing crossover differences over a cycle. We used T-T, P-P, and T-P crossover differences after the $20.5-\mathrm{cm}$ TOPEX/POSEIDON relative bias was corrected. Crossovers in regions shallower than $1000 \mathrm{~m}$ and crossovers with differences larger than 30 $\mathrm{cm}$ were also rejected. This removes less than $5 \%$ of crossovers whose differences are probably polluted by other signals than the orbit error.

Our method is a constrained sinusoidal adjustment [Tai, 1988]. The orbit error is parameterized over each group $i$ of two revolutions as the sum of a constant and two sinusoids at one and two cycles per revolution as follows:

$$
\operatorname{orb}_{i}(t)=a_{i o}+\sum_{m=1}^{2} a_{i m} \cos \left(\frac{2 \Pi}{m T} t\right)+b_{i m} \sin \left(\frac{2 \Pi}{m T} t\right)
$$

The crossover differences yield the following linear system:

$$
\mathbf{Z}=\mathbf{H X}+\mathbf{V}
$$

where $\mathbf{Z}$ is the vector of crossover differences, $\mathbf{H}$ is the observation matrix, $\mathbf{X}$ is the vector of unknowns (coefficients $a_{i o}, a_{i m}$, and $b_{i m}$ ), and $\mathbf{V}$ the vector of residuals (other altimetric signals or noise in crossover differences). There are about 320 unknowns and typically 6000 crossovers for a given cycle. The system (2) can be solved in the context of optimal estimation theory. The optimal estimation $\hat{\mathbf{X}}$ of $\mathbf{X}$ is given by [e.g., Liebelt, 1967; Tai, 1988] (assuming that the state vector $\mathbf{X}$ and noise $\mathbf{V}$ are uncorrelated):

$$
\hat{\mathbf{X}}=\left[\mathbf{R}_{\mathbf{X X}}^{-1}+\mathbf{H}^{\mathrm{T}} \mathbf{R}_{\mathrm{VV}}^{-1} \cdot \mathbf{H}\right]^{-1} \mathbf{H}^{\mathrm{T}} \cdot \mathbf{R}_{\mathrm{VV}}^{-1} \mathbf{Z}
$$

where $\mathbf{R}_{\mathrm{YV}}=\mathbf{E}\left(\mathrm{V}^{\mathrm{T}} \mathbf{V}\right)$ is the a priori covariance matrix of residuals and $\mathbf{R}_{\mathbf{X X}}=\mathbf{E}\left(\mathbf{X}^{\mathrm{T}} \mathbf{X}\right)$ is the a priori covariance matrix of orbit error parameters. It can be shown that $\hat{X}$ is the solution which minimizes the following quantity:

$$
(\mathbf{H X}-\mathbf{Z})^{\mathrm{T}} \mathbf{R}_{\mathrm{VV}}^{-1} \cdot(\mathbf{H X}-\mathbf{Z})+\mathbf{X}^{\mathrm{T}} \mathbf{R}_{\mathbf{X X}}^{-1} \mathbf{X}
$$

That is, the crossover differences are minimized but the solution itself is also minimized. This additional constraint removes the singularity of the crossover adjustment problem $[$ Tai, 1988]. For the sake of simplicity and because of the large number of crossovers, $\mathbf{R}_{\mathrm{Vv}}$ the noise covariance matrix was chosen to be diagonal (no a priori noise correlation). The noise variance should correspond to the crossover difference variance once the orbit error is corrected. To take into account the ocean variability, it was chosen to range between 25 and $80 \mathrm{~cm}^{2}$ for crossover time lags between 0 and 10 days. $\mathbf{R}_{\mathrm{Xx}}$ was not assumed, however, to be diagonal. A correlation of 0.7 was assigned between consecutive groups to better constrain the orbit error estimation. The a priori variance for each parameter was set to $5 \mathrm{~cm}^{2}$ yielding an a priori variance for the orbit error of $25 \mathrm{~cm}^{2}$.

The adjustment reduces the T-T, T-P, and P-P crossover differences from $10.1,10.6$, and $10.6 \mathrm{~cm}$ to $8.8,9.2$, and 9.2 $\mathrm{cm}$, respectively. The variance reduction is $25 \mathrm{~cm}^{2}$ which would correspond to an RMS orbit error of about $3.5 \mathrm{~cm}$. This is certainly an upper estimate of the real orbit error since our orbit error estimation also contains part of the other altimetric signals with timescales shorter than 10 days. In particular, part of the remaining tidal signals are probably absorbed in the solution. The global RMS value of the orbit error for the 29 processed cycles is only $3.2 \mathrm{~cm}$. Larger orbit errors are found in the South Atlantic, Indian Ocean, and central Pacific. These are probably due to tidal errors (see section 4.1). Further analyses are needed to determine the relative contribution of real orbit error and other signals. The geographical distribution of the RMS crossover differences after and before orbit error reduction differs only slightly which is again related to the small residual orbit errors. Figure $3 \mathrm{a}$ shows the orbit error estimation for a particular day of cycle 22 . Maximum amplitudes are below $7 \mathrm{~cm}$. The orbit error spectrum (Figure 3b) shows energy at daily frequency in addition to the one-cycle and two-cycle per revolution frequencies. The one-cycle per revolution frequency is generally much more energetic than the two-cycle per revolution frequency. Both one-cycle and two-cycle frequencies have daily modulations.

The orbit error reduction method is only a first attempt to extract the very small TOPEX/POSEIDON orbit error from altimeter data. The problem is not an easy one and may even be impossible to solve. Dedicated studies need now to be carried out. The results basically show that the orbit error is very small but our estimation is likely contaminated by other altimetric signals. More accurate orbit error estimates will be possible, in particular, when better tide models are available. More generally, there is a need to progress simultaneously on all altimetric corrections to get better estimates of the orbit error. The orbit error reduction methods could also probably be improved by using a better a priori description of the spatial and temporal characteristics of the orbit error and of the ocean signal and remaining altimetric errors [e.g., Mazzega and Houry, 1989; Blanc et al., 1994].

\section{Repeat-Track Analysis}

In this section a global repeat-track analysis of TOPEX/ POSEIDON data is performed. The RMS sea level variability and large-scale sea level variability maps are analyzed and the sensitivity to orbit error and tidal errors is assessed. Wavenumber spectra of sea level variability are then calculated to estimate the noise level of the POSEIDON and TOPEX altimeters and analyze the wavenumber spectral characteristics of sea level variability measured by TOPEX/ POSEIDON.

\subsection{RMS of Sea Level Anomaly and Influence of Orbit and Tidal Errors}

Sea level anomaly (SLA) was calculated using the conventional repeat-track analysis method. Data corrected for all altimetric errors are first resampled every $7 \mathrm{~km}$ using a cubic spline. The most complete profile is then selected and the differences with respect to the other cycles are calculated. Data are then recentered relative to another cycle or to the mean. A few spikes still present in the SLA data are removed using the same scheme as described in section 2 . This removes essentially about $1.5 \%$ of POSEIDON data, TOPEX data being smoother. Finally, data were low-pass filtered using a Lanczos filter with a cutoff wavelength of 70 $\mathrm{km}$. To test the sensitivity to initial orbit error, two SLA files were calculated with and without our orbit error correction. The RMS SLA was then obtained by averaging data over 


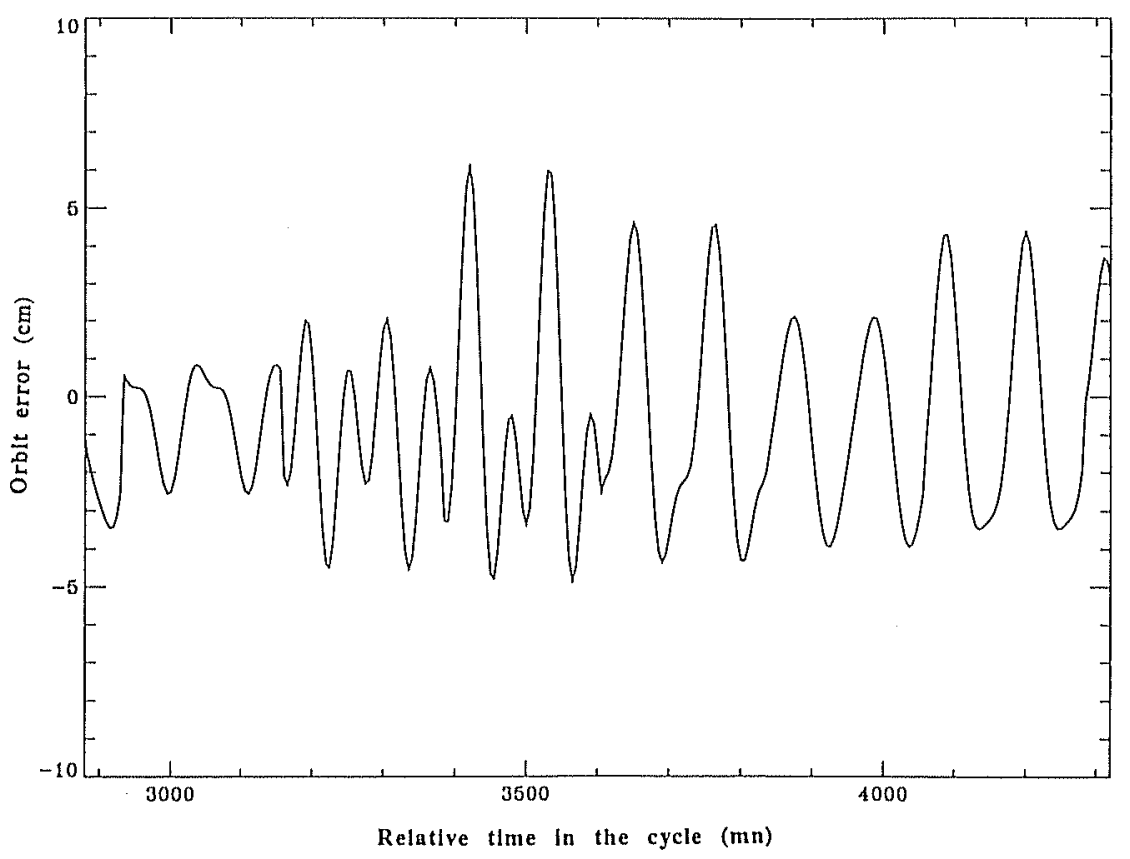

Figure 3a. TOPEX/POSEIDON orbit error estimation for a particular day of cycle 22. Units are centimeters.

boxes of $2^{\circ}$ in latitude by $3^{\circ}$ in longitude. Plate 1 represents the RMS variation of SLA relative to the mean for cycle 2 to cycle 30 . No orbit error correction was applied and the CR tide model is used. The areas of strong ocean variability related to major ocean currents (Gulf Stream, Kuroshio, Brazil/Malvinas confluence region, Antarctic Circumpolar Current) are prominent. The map agrees well with the Geosat results [e.g., Koblinsky, 1988]. In areas with low ocean variability, the RMS variability of the sea level is typically $6 \mathrm{~cm}$. This is already a very impressive result in that, unlike previous altimeter missions, this result is achieved without removing long-wavelength signals. As will be seen below, this figure is reduced again using a better tide model. We did a similar calculation using our orbit error correction. The RMS value in low-energy regions are only slightly reduced to $5 \mathrm{~cm}$ RMS. The mean global RMS value is reduced from 9.6 to $9.2 \mathrm{~cm}$. This shows again that the orbit error does not affect the results much. This is both because the orbit error is low and because the gravitational orbit error is cancelled on repeat-track differences [e.g., Engelis, 1987; Balmino, 1992].

Tidal errors are now probably more important than orbit

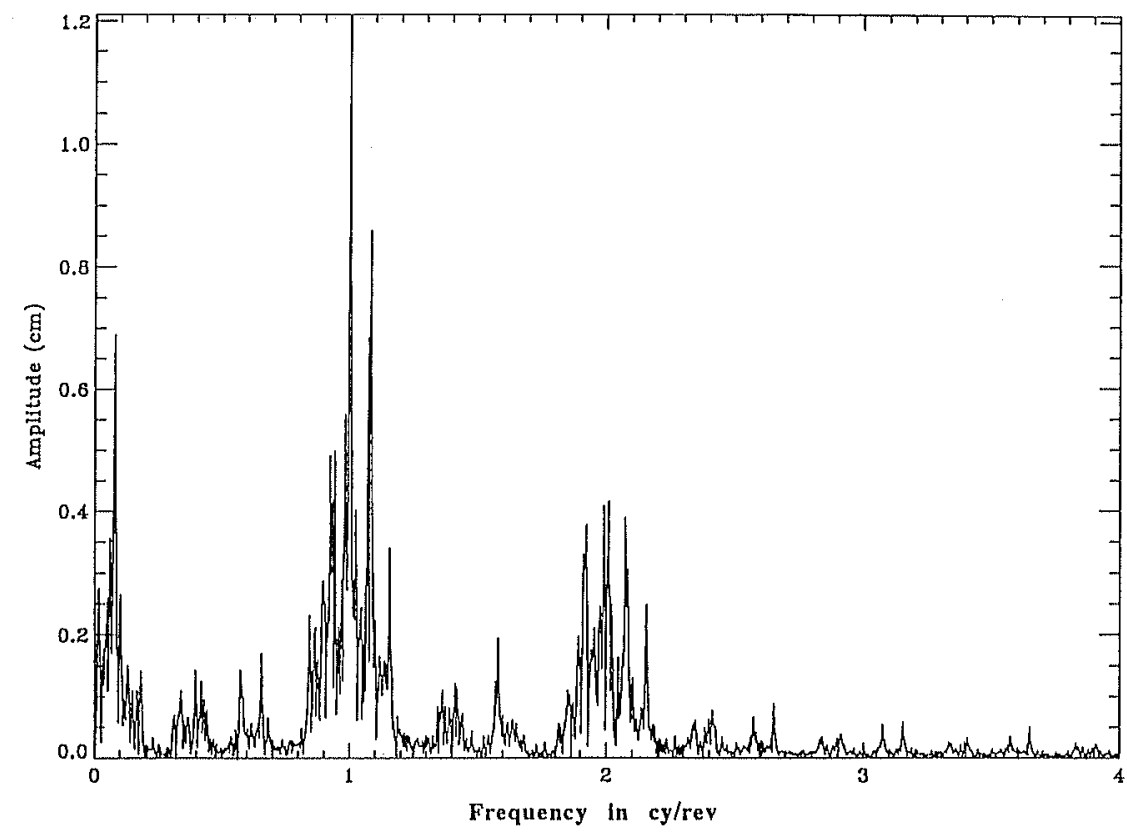

Figure 3b. TOPEX/POSEIDON orbit error spectrum for cycle 22. 


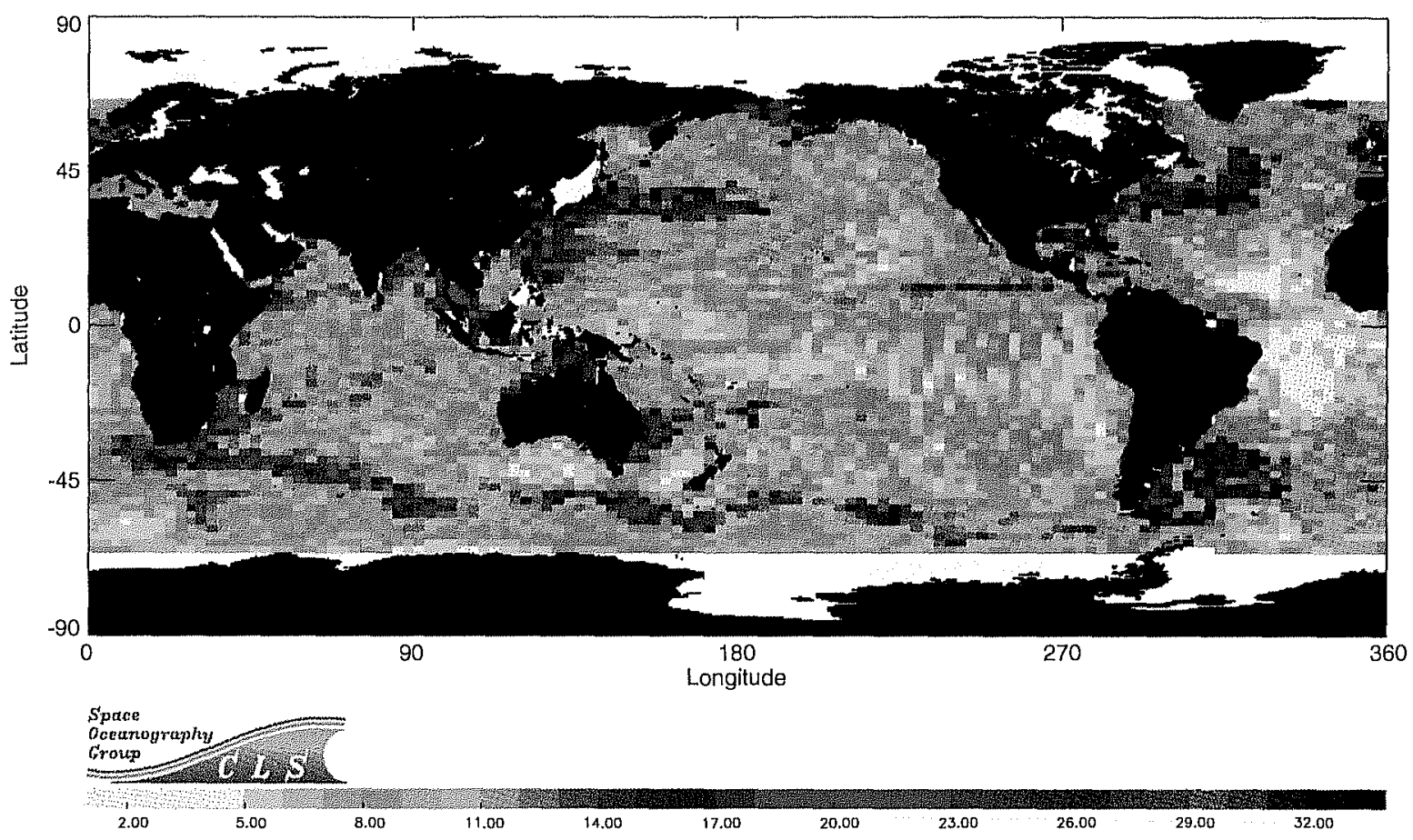

Plate 1. RMS SLA relative to the mean for cycle 2 to cycle 30 . Units are centimeters. No orbit error correction was applied, and the Cartwright and Ray [1990] tide model is used.

errors. The aliased period for the $\mathrm{M}_{2}$ and $\mathrm{S}_{2}$ tides for TOPEX/POSEIDON are 62.1 and 58.7 days, respectively. The 60-day period signal was thus extracted from the SLA data following the method used by Le Traon and Minster. [1993]. Since a 60-day period is not a dominant mode of ocean variability, this is a good way of setting an upper limit on the relative contribution of tidal signals in SLA maps. The 60-day period signal contributes very significantly to the total SLA signal in regions of low ocean variability (Plate 2 ). In particular, it accounts for about $40 \%$ of the total signal variance in the southeastern Pacific and southeastern Atlantic where the Cartwright and Ray model is known to be inaccurate [e.g., Ray, 1993]. In the Mediterranean Sea the 60 -day period signal accounts for less than $10 \%$ of the total

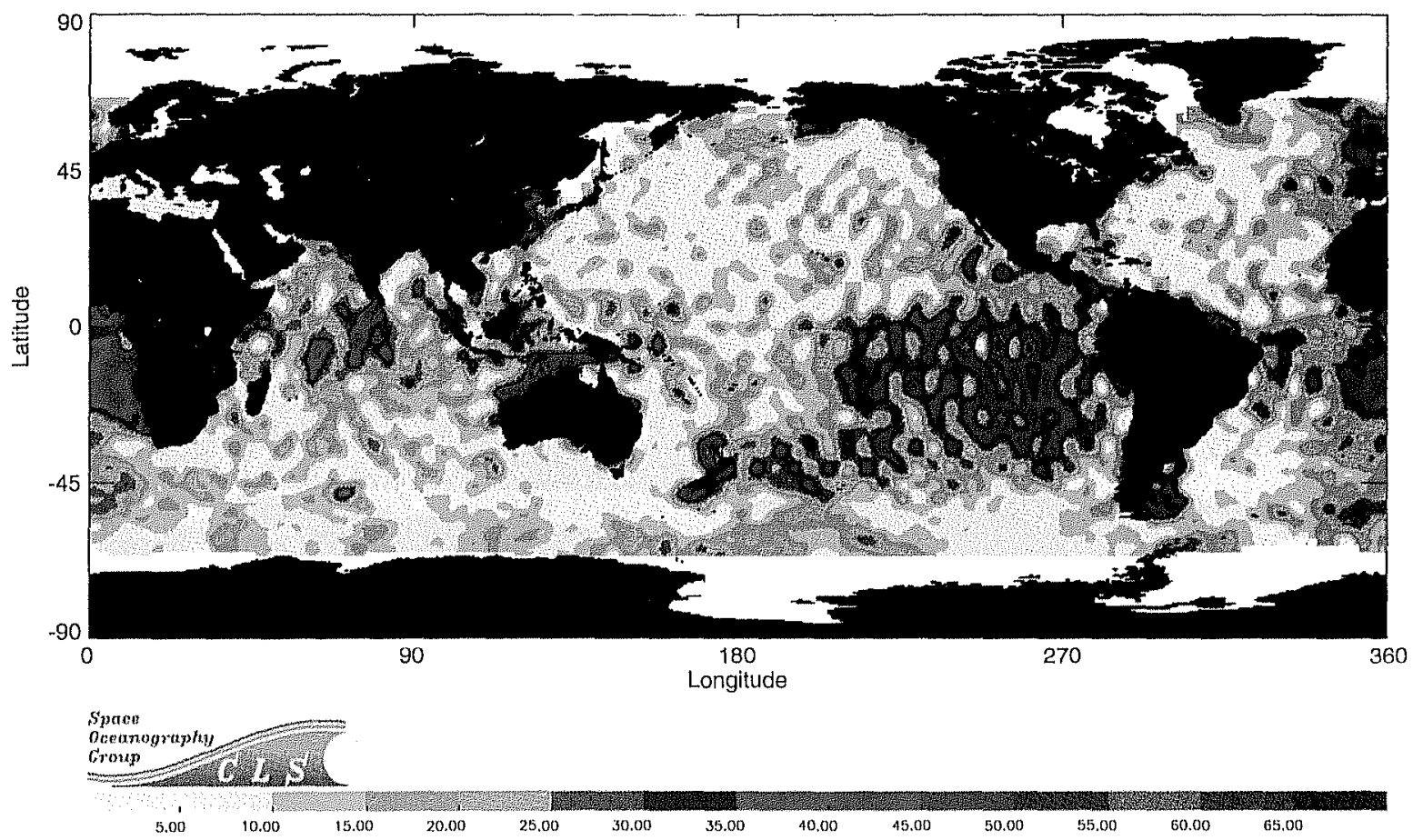

Plate 2. Relative variance (in percent) of the 60-day period signal. 


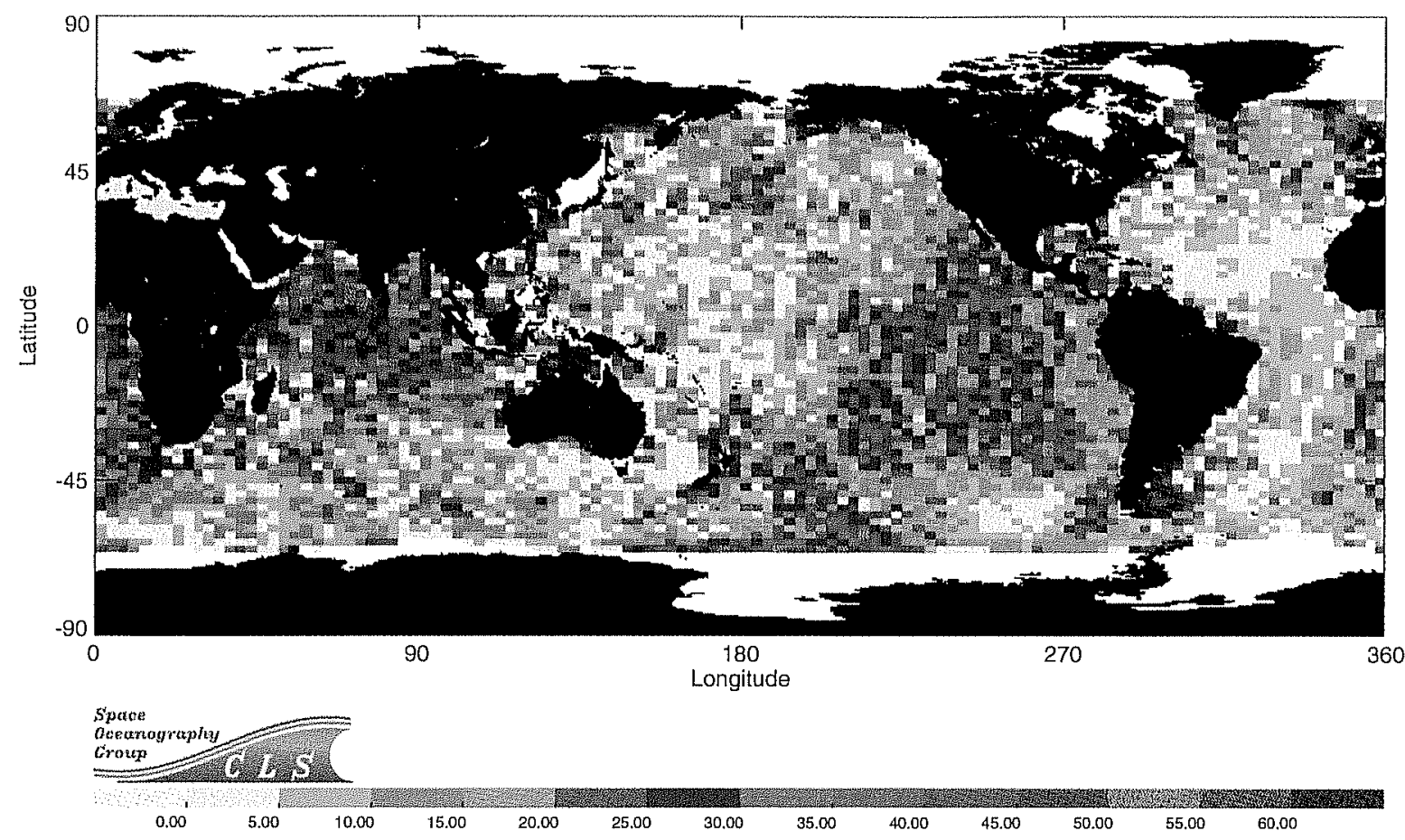

Plate 3. Difference in SLA variance using the Cartwright and Ray [1990] tide model and SLA variance using the University of Texas (UTA) tide model based on TOPEX/POSEIDON data. Units are $\mathrm{cm}^{2}$.

signal variance. This is a good external validation of the $\mathrm{P}$. Canceil et al. (unpublished manuscript, 1994) model.

The fact that tidal signals are clearly visible in TOPEX/ POSEIDON data (which is again related to the low orbit error) means that it should be fairly easy to extract tides from TOPEX/POSEIDON data. A preliminary global tide model based on TOPEX/POSEIDON data was recently made available by the University of Texas (UTA) [Ma et al.,

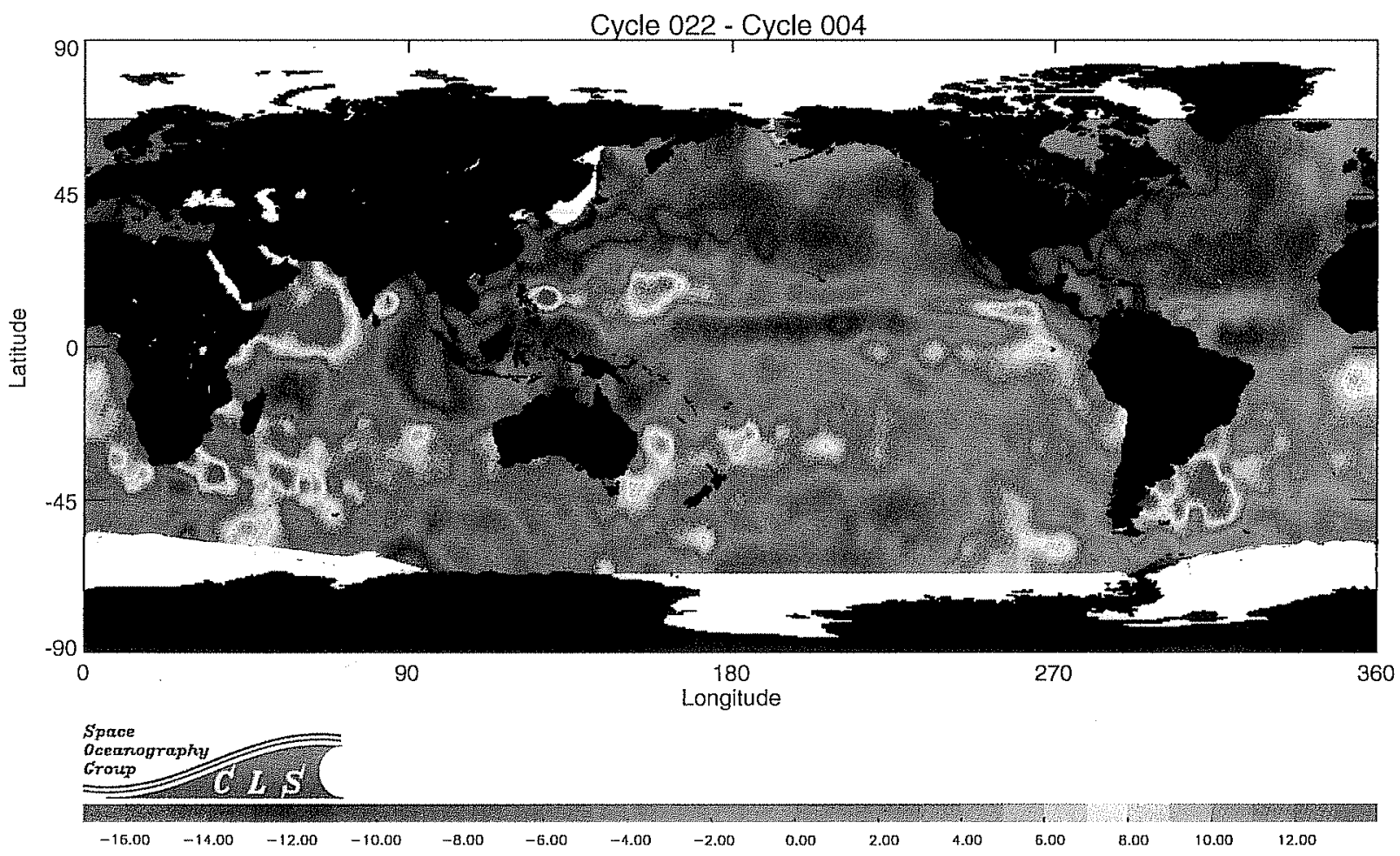

Plate 4. Difference between cycle 4 and cycle 22. Data were averaged over boxes of $4^{\circ}$ latitude by $4^{\circ}$ longitude. Units are centimeters. No orbit error correction was applied. This figure shows the global annual cycle of sea level. 
this issue]. Its accuracy for the main tidal constituents is estimated at 2 or $3 \mathrm{~cm} \mathrm{RMS}$, that is, about twice as good as the CR model. The new tide model considerably improves the RMS sea level anomaly (which is, of course, expected since the model used TOPEX/POSEIDON data). The reduction of sea level variance relative to the CR model (Plate 3 ) is $(4 \mathrm{~cm})^{2}$ on average but can reach $(8 \mathrm{~cm})^{2}$ in the southeast Pacific, southeast Atlantic, and Indian Oceans. These are the regions where we found a large relative variance in the 60-day period signal. The RMS sea level variability thus decreases from $6 \mathrm{~cm}$ to only $4 \mathrm{~cm}$ in quiet ocean regions. The RMS of SLA in the North Atlantic was also calculated using the Institut de Mécanique de Grenoble hydrodynamical model. This model accuracy is about $2 \mathrm{~cm}$ RMS [Le Provost et al., this issue]. The variance reduction relative to the CR model over the North Atlantic is about $(3.5 \mathrm{~cm})^{2}$. It is comparable to the UTA tide model result in the North Atlantic (see Plate 3) which is remarkable since the model does not use any TOPEX/POSEIDON data.

\section{₫.2. Large-Scale Sea Level Variability and Mean Sea Level Variations}

Because of very low orbit errors, the large-scale sea level variability can be observed for the first time with satellite altimetry. This is illustrated by Plate 4 which shows the difference between cycle 4 (October 22 to November 1, 1992) and cycle 22 (April 19 to April 29, 1993). This difference is over a multiple of 60 days and is thus almost unaffected by $M_{2}$ and $S_{2}$ tidal errors. Data were averaged on $4^{\circ}$ longitude by $4^{\circ}$ latitude boxes and a smoothing was applied between adjacent boxes. The figure shows the global annual cycle of sea level with a lowering of the sea level in the northern hemisphere. This is mostly due to the contraction of surface waters related to their cooling in fall and winter [e.g., Gill and Niiler, 1973]. The signal is stronger near the western boundary currents (Gulf Stream and Kuroshio, $-20 \mathrm{~cm}$ ) partly because these warm currents exchange more heat with the atmosphere. The same phenomenon occurs in the southern hemisphere although the signal is smaller than in the northern hemisphere. There are also, doubtless, sea level variations associated with change in the wind-driven gyrescale circulation. In particular, the lowering of the sea level in the Gulf Stream is also associated with a southward shift of the Gulf Stream mean axis. A detailed analysis of these signals is given by J. F. Minster et al. (unpublished manuscript, 1994). In the tropical Pacific and Atlantic Oceans the sea level trough and crest between $5^{\circ} \mathrm{N}$ and $15^{\circ} \mathrm{N}$ correspond to the seasonal decreases in intensity of the North Equatorial

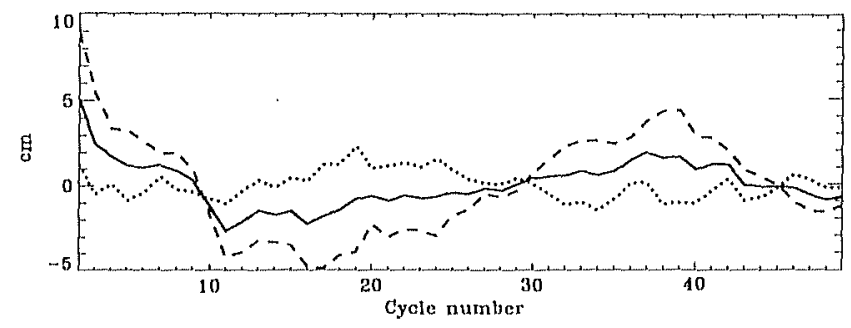

Figure 4a. Variation of the mean sea level anomaly for the northern hemisphere (dashed line), for the southern hemisphere (dotted line), and for both hemispheres (solid line) using the Carfwright and Ray [1990] tide model. Units are centimeters.

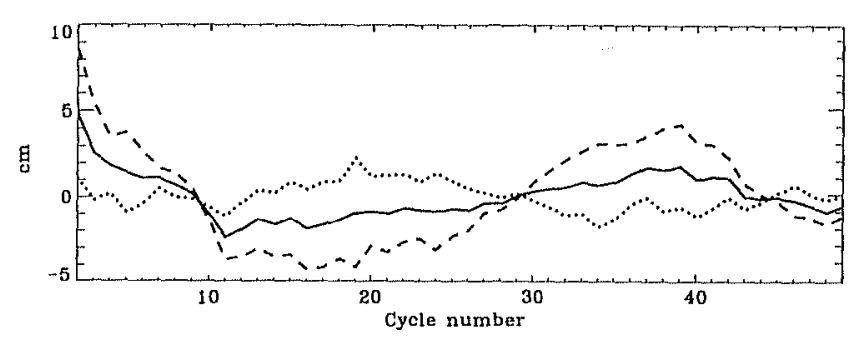

Figure $4 \mathrm{~b}$. Variation of the mean sea level anomaly for the northern hemisphere (dashed line), for the southern hemisphere (dotted line), and for both hemispheres (solid line) using the University of Texas (UTA) tide model. Units are centimeters.

Countercurrent and of the North Equatorial Current [Wyrtki, 1974; Richardson and Philander, 1987]. In the Indian Ocean the Arabian Sea large anticyclonic circulation results from monsoon reversal [Wyrtki, 1973]. The same map was calculated but with our orbit error correction applied. The changes were almost undetectable because the orbit error is very small and further reduced by spatial averaging. The RMS difference between the two maps was actually only 1 $\mathrm{cm}$ RMS (the RMS of the sea level variations between the two cycles is about $7 \mathrm{~cm}$ ).

Figure 4 a shows the mean SLA over each cycle globally and for the two hemispheres separately. The CR tide model was used. The mean was calculated from the mean of SLA data over $5^{\circ}$ latitude by $5^{\circ}$ longitude boxes since otherwise the altimetric sampling would give more weight to highlatitude regions. We used additional data (up to cycle 49) to better analyze the global annual variations in sea level. The global annual cycle of sea level is plain to see in the northern hemisphere. The sea level decreases very rapidly from October to December 1992 and starts to rise smoothly in the beginning of April 1993. It decreases again starting from October 1993. The mean sea level for the first two or three cycles is higher than for the other cycles. This may be related to the satellite attitude which was well above normal in the first TOPEX/POSEIDON cycles. However, additional data are needed to confirm this result since it could also be due to interannual variability. Sixty-day period signals due to tidal errors can also be seen. The southern hemisphere has a much smaller hemispheric signal and as a result the global mean sea level anomaly has a seasonal cycle which corresponds to the northern hemisphere seasonal cycle. Although there is some noise between successive cycles (which may

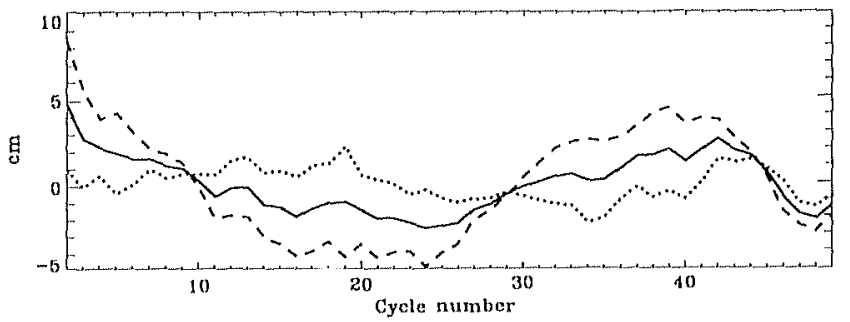

Figure $4 c$. Variation of the mean sea level anomaly for the northern hemisphere (dashed line), for the southern hemisphere (dotted line), and for both hemispheres (solid line) using the UTA tide model and a nonlocal inverse barometer correction. Units are centimeters. 
be due to real oceanic signals and/or to altimetric errors), the figure suggests that the global mean sea level over one cycle can already be measured with an accuracy of about $\pm 0.5 \mathrm{~cm}$. This is a very promising result for global mean sea level monitoring.

The mean sea level variations were also calculated with the University of Texas tide model (Figure 4b). There are only slight differences between the two estimates which means that tidal errors do not affect the mean sea level variations much. More important is the problem of the inverse barometer correction (IBC). The mean IBC over the whole ocean should be equal to zero (otherwise this would imply change in the mass of the ocean). This is not the case for our calculations since we used a constant mean pressure of 1013.3 mbar to calculate the IBC. We thus did a correction by using a nonconstant mean pressure for each cycle calculated from gridded ECMWF data, that is, we apply a nonlocal inverse barometer correction [Ponte et al., 1991]. Note that because of the nonhomogeneous space/time sampling of TOPEX/POSEIDON and because TOPEX/ POSEIDON does not cover the whole ocean, this is not equivalent to applying no inverse barometer correction at all. As can be seen from Figure 4c, the use of a nonlocal IBC affects the mean sea level variations significantly. In particular, the mean sea level decreases less rapidly during the first cycles and more rapidly during the last cycles. The exact response of the mean sea level to pressure forcing still remains, however, an open question and should be studied in depth with TOPEX/POSEIDON data [e.g., Fu and Pihos, this issue].

\subsection{Wavenumber Spectra of Sea Level Anomaly}

To estimate the spectral characteristics of TOPEX and POSEIDON altimeters separately, we first computed the mean wavenumber spectra of the TOPEX-TOPEX (T-T), POSEIDON-POSEIDON (P-P), and TOPEX-POSEIDON (T-P) sea level differences. The spectral analyses are as described by Le Traon and Minster [1993]. Unfiltered profiles were first divided into segments of $40^{\circ}$ in latitude. Wavenumber spectra were calculated using almost complete segments (gaps were filled by linear interpolation) by fast Fourier transform and mean spectra were obtained by averaging individual spectra over latitude and longitude boxes. The T-T and T-P wavenumber spectra were calculated using cycle 21 as a reference and using TOPEX and POSEIDON data from cycle 2 to cycle 30 . The P-P wavenumber spectrum used cycle 20 as a reference and all cycles where POSEIDON was working (cycle 31 included). We used first all tracks in the tropical/equatorial regions between $20^{\circ} \mathrm{S}$ and $20^{\circ} \mathrm{N}$ and in the midlatitude regions between $20^{\circ} \mathrm{N}$ and $60^{\circ} \mathrm{N}$ and $20^{\circ} \mathrm{S}$ and $60^{\circ} \mathrm{S}$. The three wavenumber spectra for tropical and midlatitudes regions are shown on Figures $5 \mathrm{a}$ and $5 \mathrm{~b}$, respectively. The number of profiles for T-T, T-P, and P-P is about 9000,1000 , and 600 for midlatitude and spectra. The number of profiles for tropical spectra is about twice as small. The confidence intervals were calculated assuming a decorrelation of one profile over three. In midlatitude regions the mean along-track wavenumber spectra show the now classic three-segment pattern [Le Traon et al., 1990; Le Traon and Minster, 1993]. Between 100 and 500 to $600 \mathrm{~km}$ they have steep slopes ranging from -3 to -4 . For longer wavelengths, the spectra are less steep or flat. In the tropical regions, the spectra have slopes of around -2 and no clear breaks in the slopes are observed which means that the signal is dominated by large scales. All these spectral characteristics agree very well with the Geosat results [Le Traon et al., 1990; Le Traon and Minster, 1993]. While T-T, T-P, and P-P spectra agree well at low wavenumbers, they present different characteristics for wavelengths shorter than $100 \mathrm{~km}$. The T-T spectrum remains red and does not show a clear white noise plateau. The mitnimum spectrum value is about $90 \mathrm{~cm}^{2} / \mathrm{cycle} / \mathrm{km}$ which would translate into noise of about $1.8 \mathrm{~cm}$ only (taking into account the $\sqrt{2}$ factor since spectra are calculated from differences between cycles). The P-P spectrum shows a clear white noise signal up to wavelengths of $30 \mathrm{~km}$. The repeat-track noise is about $3.5 \mathrm{~cm}$ RMS. Note that this figure is reduced to slightly less than 3 $\mathrm{cm}$ with improved retracking algorithms. (These modifications have been implemented on board since cycle 41.) There is a large difference, however, between TOPEX and POSEIDON between 50 and $100 \mathrm{~km}$ which apparently cannot be attributed to noise. POSEIDON seems to see signals about twice as energetic as TOPEX. This can also be seen in T-P spectrum. This may be related to TOPEX altimeter tracker characteristics. In particular, Rodriguez. and Martin [this issue] have shown that the way the acceleration correction is made in the TOPEX GDRs has the effect of severely attenuating the spectrum in the $6-60 \mathrm{~km}$ wavelength band. Although most of the acceleration drops out in repeat-track differences, the acceleration due to the change in oceanic signals will remain. The correction is anticorrelated with the signal [Rodriguez and Martin, this issue, equation (3)] and is only valid in the low-frequency part of the spectrum. It will thus remove a very significant part of the variable oceanic signal at high frequencies. Given the TOPEX tracker characteristics as given by Rodriguez and Martin [this issue], the acceleration correction thus amounts to a $50 \%$ reduction of the variance of a $35-\mathrm{km}$ wavelength oceanic signal. The TOPEX and POSEIDON spectra relative to the mean over cycle 2 to cycle 30 are also shown on Figure $5 \mathrm{c}$ for tropical regions and Figure $5 \mathrm{~d}$ for midlatitude regions. They show the same characteristics as above. In addition, POSEIDON spectra are in better agreement with spectra calculated in similar conditions with Geosat data [Le Traon et al., 1990].

\section{Conclusion}

These first analyses demonstrate the high quality of TOPEX/POSEIDON data. The major improvement compared to previous altimetric missions comes from the orbit error. Orbit accuracy is better than $5 \mathrm{~cm}$. This will allow us for the first time to study the large-scale sea level variability. The residual orbit error can probably be reduced to a few centimeters using global crossover minimization, but these methods need to be used with care given the low signal-tonoise ratio. POSEIDON and TOPEX altimeters compare very well, and the two data sets can be merged in the analyses provided the relative biases are corrected and adapted em bias corrections are used. The spectral characteristics of TOPEX and POSEIDON agree well at low wavenumbers but differ at short wavelengths because of TOPEX tracker characteristics and to the way the acceleration correction is made in the GDRs. Repeat-track noise levels for 1 -s averages are estimated at $3 \mathrm{~cm}$ for POSEIDON and $1.8 \mathrm{~cm}$ for TOPEX, but the TOPEX noise probably 

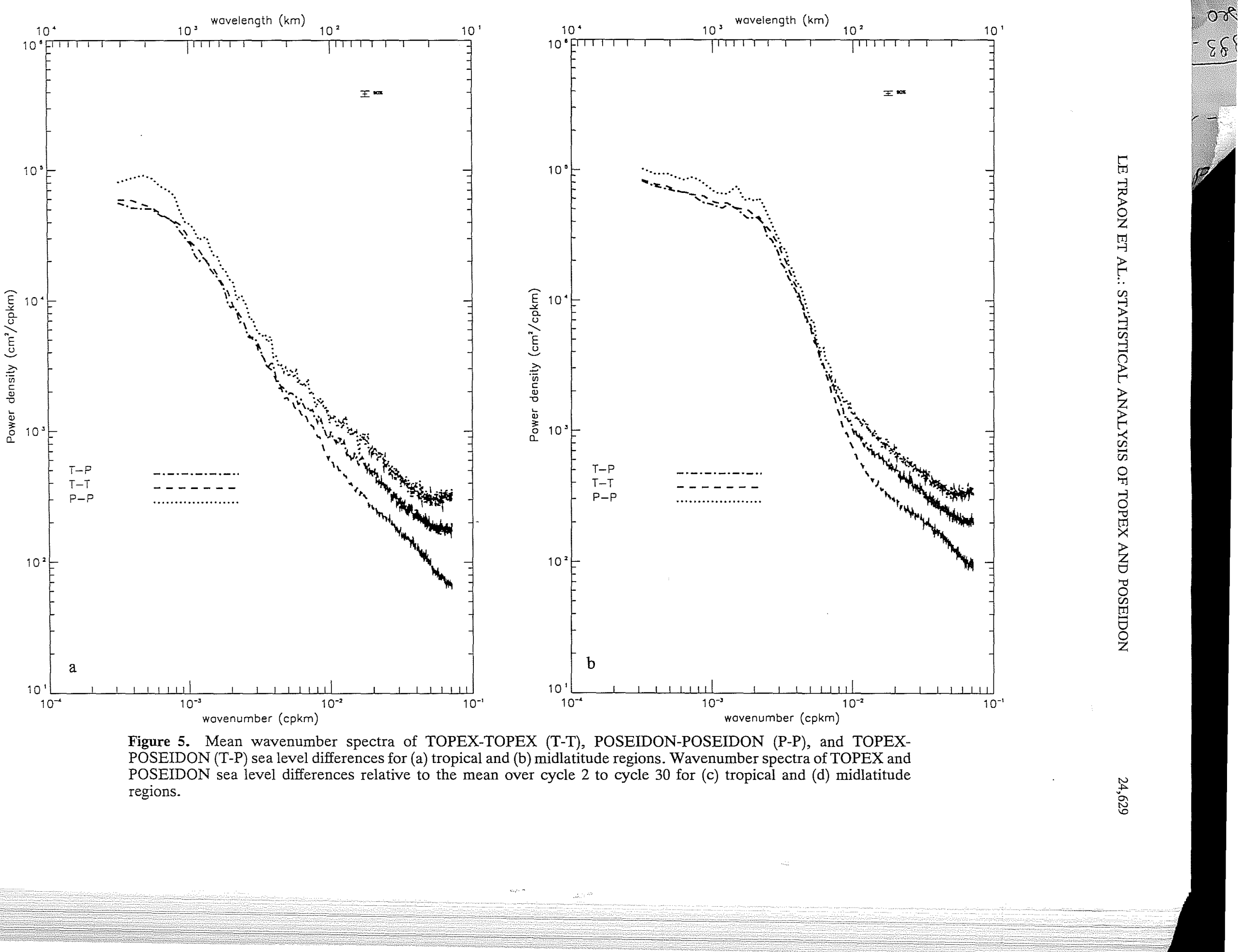

Figure 5. Mean wavenumber spectra of TOPEX-TOPEX (T-T), POSEIDON-POSEIDON (P-P), and TOPEXPOSEIDON sea level differences relative to the mean over cycle 2 to cycle 30 for (c) tropical and (d) midlatitude regions. 


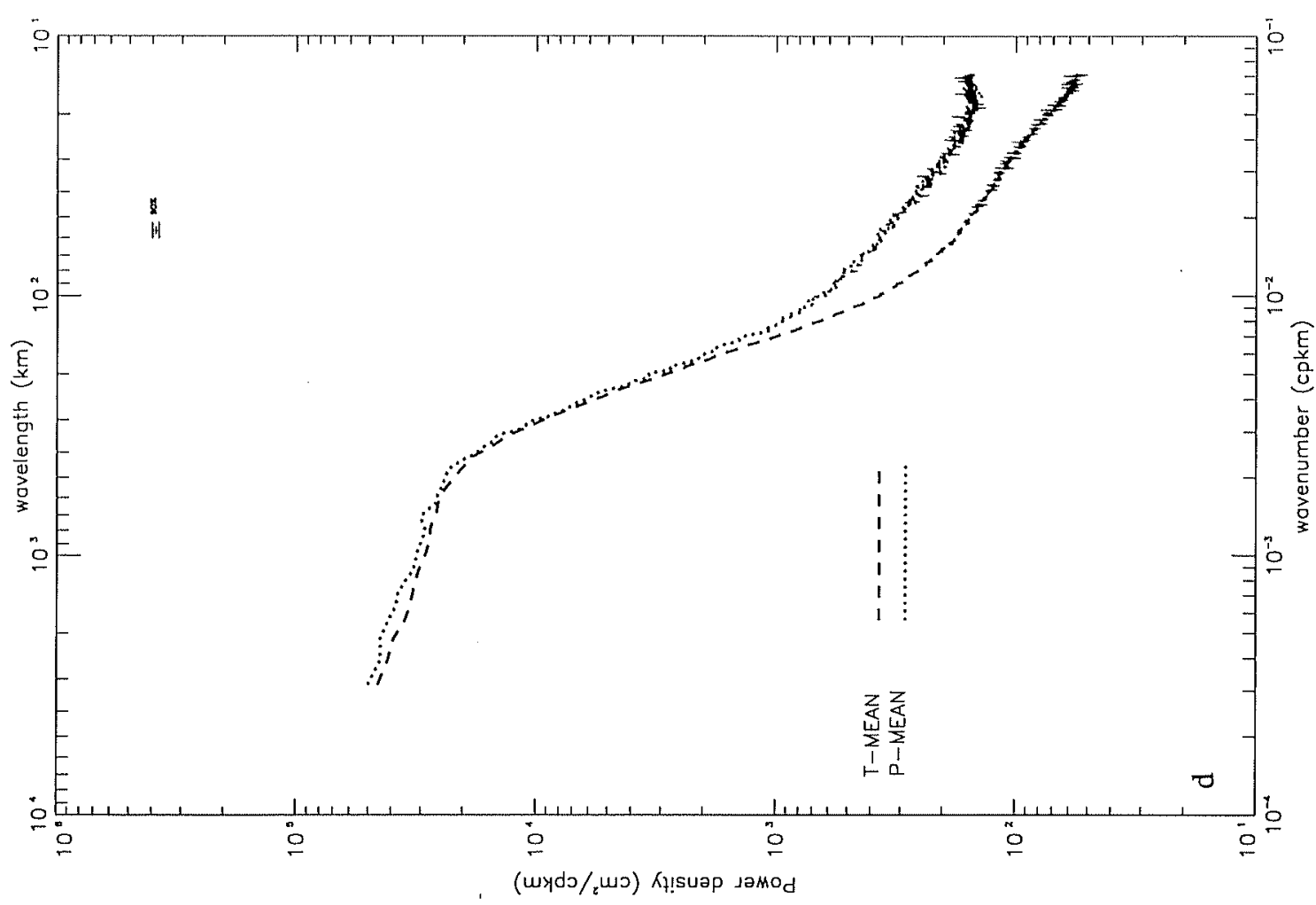

몸

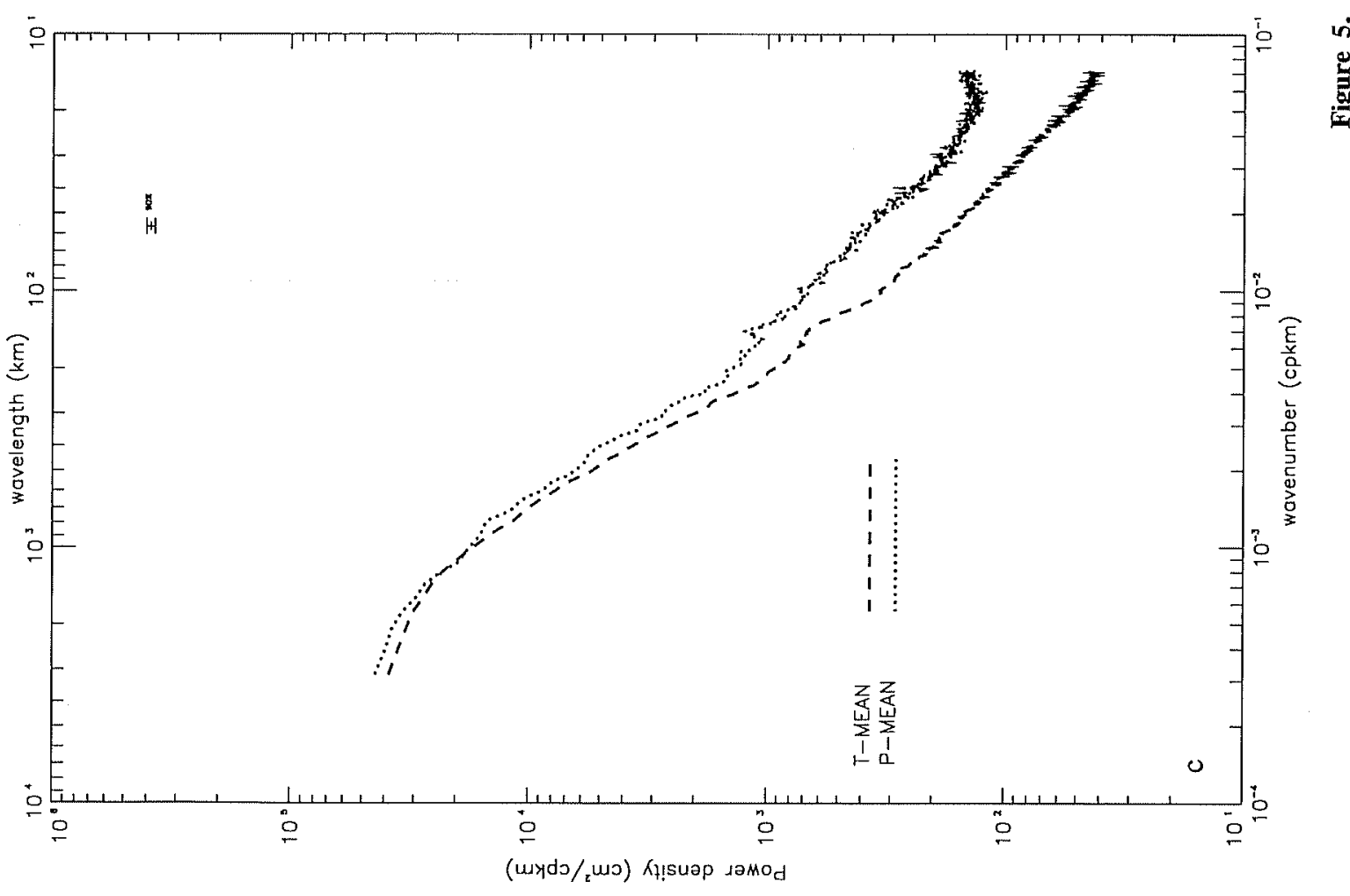


corresponds to averages over several seconds. The most significant remaining error in TOPEX/POSEIDON GDR data is due to ocean tides but results obtained with a preliminary global tide model based on TOPEX/POSEIDON data are very encouraging. Other corrections will also become important. In particular, inverse barometer and em bias effects now need to be studied in depth, and their impact on the large-scale variability and mean sea level should be quantified. These preliminary results already show, however, that the large-scale sea level variability will be mapped with unprecedented accuracy by TOPEX/POSEIDON.

Acknowledgments. Programming support by P. Sicard is acknowledged. N. Greenwood helped with the English style and clarity.

\section{References}

AVISO, AVISO User Handbook: Merged TOPEX/POSEIDON products, Rep. AVI-NT-02-101-CN, 2nd ed., CNES, Toulouse, France, 1992.

Balmino, G., Radial orbit error theory, in Lecture Notes in Earth Sciences, vol. 50, Satellite Altimelry in Geodesy and Oceanography, edited by R. Rummel and F. Sanso, pp. 243-315, SpringerVerlag, New York, 1992.

Blanc, F., P. Y. Le Traon, and S. Houry, A new method to extract mesoscale variability from altimetry, J.Atmos. Oceanic Technol., in press, 1994.

Cartwright, D. E., and R. D. Ray, Oceanic tides from Geosat altimetry, J. Geophys. Res., 95, 3069-3090, 1990.

Cartwright, D. E., and R. J. Taylor, New computations of the tide-generating potential, Geophys. J. R. Astron. Soc., 33, 253$264,1971$.

Christensen, E. J., C. S. Morris, B. J. Williams, J. R. Guinn, B. J. Haines, C. K. McColl, R. A. Norman, S. J. Keihm, D. A. Imel, and G. H. Born, Calibration of TOPEX/POSEIDON at Platform Harvest, J. Geophys. Res., this issue.

Engelis, $\mathrm{T}$., Radial orbit error reduction and sea surface topography determination using satellite altimetry, Rep. 377, Dep. of Geod. Sci. and Surv., Ohio State Univ., Columbus, 1987.

Fu, L. L., and R. Glazman, The effect of the degree of wave development on the sea state bias in radar altimetry measurement, J. Geophys. Res., 96, 829-834, 1991.

Fu, L. L., and G. Pihos, Determining the response of sea level to atmospheric pressure forcing using TOPEX/POSEIDON data, $J$. Geophys. Res., this issue.

Gaspar, P., F. Ogor, P. Y. Le Traon, and O. Z. Zanife, Estimating the sea state bias of the TOPEX and POSEIDON altimeters from crossover differences, J. Geophys. Res., this issue.

Gill, A. E., and P. P. Niiler, The theory of the seasonal variability in the ocean, Deep Sea Res., 20, 141-177, 1973.

Koblinsky, C., Geosat versus Seasat, Eos Trans. AGU, 69, 1026, 1988.

Le Provost, C., M. L. Genco, F. Lyard, P. Vincent, and P. Canceil, Spectroscopy of the world ocean tides from a hydrodynamic finite element model, J. Geophys. Res., this issue.

Le Traon, P. Y., and J. F. Minster, Sea level variability in the South Atlantic subtropical gyre: Semiannual Rossby waves and largescale signal, J. Geophys. Res., 98, 12,315-12,326, 1993.

Le Traon, P. Y., M. C. Rouquet, and C. Boissier, Spatial scales of mesoscale variability in the North Atlantic as deduced from Geosat data, J. Geoplys. Res., 95, 20,267-20,285, 1990.

Liebelt, P. B., An Introduction to Optimal Estination, 273 pp., Addison-Wesley, Reading, Mass., 1967.

Ma, X. C., C. K. Shum, R. J. Eanes, and B. D. Tapley, Determination of ocean tides from the first year of TOPEX/POSEIDON altimeter measurements, J. Geophys. Res., this issue.

Mazzega, P., and S. Houry, An experiment to invert Seasat altimetry for the Mediterranean and Black Sea mean surfaces, Geophys. J., 96, 259-272, 1989.

Ménard, Y., E. Jeansou, and P. Vincent, Calibration of the TOPEX/ POSEIDON altimeters at Lampedusa: Additional results at Harvest, $J$. Geophys. Res., this issue.

Nouel, F., et al., Precise Centre National d'Etudes Spatiales orbits for TOPEX/POSEIDON: Is reaching $2 \mathrm{~cm}$ still a challenge?, $J$. Geophys. Res, this issue.

Ponte, R. M., D. A. Salstein, and R. D. Rosen, Sea level response to pressure forcing in a barotropic numerical model, $J$. P/ys. Oceanogr., 21, 10,043-10,057, 1991.

Ray, R. D., Global ocean tide models, IEE Trans. Geosci. Remote Sens., 31, 355-364, 1993.

Ray, R. D., and B. V. Sanchez, Radial deformation of the Earth by oceanic tidal loading, NASA Tech. Memo., 100743, 1989.

Ray, R. D., C. J. Koblinsky, and B. D. Beckley, On the effectiveness of Geosat altinjeter corrections, Int. J. Remote Sens., I2, 1979-1984, 1991.

Richardson, P. L., and S. G. H. Philander, The seasonal variations of surface currents in the tropical Atlantic Ocean: A comparison of ship drift data with results from a general circulation model, $J$. Geoplys. Res., 92, 715-724, 1987.

Rodriguez, E., and J. Martin, Assessment of the TOPEX altimeter performance using waveform retracking, $J$. Geophys. Res., this issue.

Schwiderski, E. W., On charting global tides, Rev. Geophys., 18, 243-268, 1980.

Stewart, R., L. L. Fu, and M. Lefebvre, Science opportunities from the TOPEX/POSEIDON mission, JPL Publ., 86-18, 58 pp., 1986.

Stum, J., A comparison between TOPEX microwave radiometer, ERS 1 microwave radiometer, and European Centre for MediumRange Weather Forecasting derived wet tropospheric corrections, $J$. Geophys. Res., this issue.

Tai, C. K., Geosat crossover analysis in the tropical Pacific, 1, Constrained sinusoidal crossover adjustment, J. Geophys. Res., 93, 10,621-10,629, 1988.

Tai, C. K., and L. L. Fu, On crossover adjustment in satellite altimetry and its oceanographic implications, J. Geophys. Res., 91, 2549-2554, 1986.

Wyrtki, K., Physical oceanography of the Indian Ocean, in The Biology of the Indian Ocean, pp. 18-36, Springer-Verlag, New York, 1973.

Wyrtki, K., Sea level and seasonal fluctuations of the equatorial currents in the western Pacific Ocean, J. Phys. Oceanogr., 4, 91-103, 1974.

J. Dorandeu, P. Gaspar, P. Y. Le Traon, and J. Stum, CLS Space Oceanography Group, 18, avenue Edouard Belin, 31055 Toulouse Cedex, France.

P. Vincent, Centre National d'Etudes Spatiales, Division TerreUnivers, 18, avenue Edouard Belin, 31055 Toulouse Cedex, France.

(Received November 29, 1993; revised April 26, 1994; accepted April 26, 1994.) 